\title{
AIR QUALITY ENSEMBLE FORECAST COUPLING ARPEGE AND CHIMERE OVER WESTERN EUROPE
}

Carvalho Ana C. (a), Laurent Menut (a), Robert Vautard (b) and Jean Nicolau (c)

(a) Laboratoire de Météorologie Dynamique, IPSL, Ecole Polytechnique, 91128 Palaiseau Cedex, France

(b) Laboratoire des Sciences du Climat et de l'Environnement, CEA, Orme des Merisiers, 91190 Gif sur Yvette Cedex, France,

(c) DPREVI/COMPAS, Meteo-France, 42 Avenue G.Coriolis, 31100 Toulouse, France

\begin{abstract}
The quality enhancement of the results encountered on numerical weather prediction ensemble runs has encouraged the air quality modellers' community to test the same methodology to foresee air pollutants concentrations in the atmosphere. In air quality forecast it is important to know in advance if the event exceedences of a certain threshold value will happen in order to implement mitigation measures concerning air pollutant emission. The ensemble approach allows giving this information within a probability range.

Within this work both perturbation on the circulation model and the chemical transport model will be implemented. The ensemble system is composed by the numerical weather prediction model ARPEGE, the meteorological model MM5 and the chemical transport model CHIMERE. Meteorological perturbations will be addressed firstly by a set of 10 ensemble members derived by the ARPEGE model, plus a control run, which will force MM5 simulations. Since the concept of air pollution ensemble forecast is not the same than the one for meteorology, we propose here an original approach for the chemistry-transport model perturbations based on previously done CHIMERE sensitivities studies: focus will be made on plausible emissions scenarios and different daily emissions profiles, boundary layer evolution, vertical mixing and photolysis rates. The ensemble based simulations will cover July and August 2006, each includes the heat wave period that influenced the weather and air quality conditions of central Europe.
\end{abstract}

\section{INTRODUCTION}

The chaotic nature of the atmosphere arises in the numerical resolution of the equations that present different solutions for slightly different values of the initial conditions.

Based on the definition of the chaotic dynamical system given by Lorenz (1963), the ensemble forecast concept was initially used to estimate the dependence of weather forecasts uncertainty to the initial boundary conditions errors (Hamill et al., 2000) by the ECMWF on Europe, and by the NCEP on the United States of America. Nowadays numerical weather prediction based on operational ensembles are available in many meteorological institutions because the mean of ensemble results have shown that this methodology provides better accuracy of weather forecast than the application of any single model, Delle Monache et al., 2006a and references within. 
Due to the encouraging results encountered on ensemble predictions results from NWP, Dabberd and Miller (2000) suggest also that air quality applications will benefit from probabilistic simulations, since they permit to estimate the likelihood of a certain event and its associated probability instead of a single value produced by a deterministic model. Galmarini et al., (2004) discusses the relevance of this type of results to the decision-making process showing that ensemble analysis and its variability reduces the risk of unreliability on the ensemble results and enriches the decision making process, since the available information is improved.

\section{AIR QUALITY MODELLING SYSTEM}

The objective of this study is to incorporate the ensemble chemistry forecast into the operational mode giving this way a value for the pollutants concentrations and also the probability of its occurrence. Hence, the chosen air quality system is based on the actual one that is in used, in operational mode, in the PREV'AIR system (URL 1) since 2003. It includes the MM5 modelling system (Dudhia, 1993) and the CHIMERE chemical transport model (Vautard et al., 2001; Bessagnet et al., 2004). The EMEP (URL 2) anthropogenic emissions of $\mathrm{NO}_{x}, \mathrm{SO}_{2}, \mathrm{CO}$ and non-methane volatile organic compounds (NMVOC) are calculated and interpolated to the CHIMERE grid.

Concerning the meteorological input of this air quality system, global data are taking form the ARPEGE model used in its ensemble framework called PEARP. The ensemble comprises 11 forecast runs, a not perturbed control run, and 10 runs were the initial conditions are perturbed. The model runs with the same horizontal and vertical resolution in both modes, operational and ensemble forecast. The PEARP system is launched once a day for three days and results are considered as initial and boundary conditions for the MM5 model. The MM5 physical parameterisations used here are those described in (Chiriaco et al., 2005). The CHIMERE model settings are strictly those described in (Vautard et al., 2006). Each day, CHIMERE starts at 18H00 UTC (at D-1), runs up to $24 \mathrm{H} 00$ at D+2. The domain under study covers the Western Europe, with $54 \mathrm{~km}$ resolution, approximately, and 8 vertical levels from surface to $500 \mathrm{hPa}$.

The simulation period ranges from 19 July to 3 August in order to cover the whole highly polluted period ( 23 July to 3 August) with a reasonable chemical spin-up time.

\section{METHODOLOGY}

An ensemble design to be applied to air quality applications has more probabilities to succeed if one or more type of uncertainties sources are included, and hence if different parts of the numerical system are disturbed. In the present work, previous studies with the adjoint version of the CHIMERE model where taking into account, in order to get an insight of the factors to which the CHIMERE model was demonstrating to be more sensitive (Menut, 2003).

Concerning the sensitivity of the modelled ozone maximum (afternoon), CHIMERE shown to be mainly sensitive to morning solvent and traffic emissions as well as to ozone boundary conditions and some reactions rates (oxidation of $\mathrm{NO}$ by $\mathrm{O}_{3}$ and by $\mathrm{OH}$, the equilibrium reactions established between the acetaldehyde and the $\mathrm{NO}_{2}$, the 
oxidation of an aromatic group by the hydroxyl radical). A focus was also made on the $\mathrm{NO}_{2}$ photolysis rate. Concerning meteorological parameters temperature, wind speed and vertical diffusion coefficients are the ones that strongly affect the mode final results on ozone, $\mathrm{O}_{\mathrm{x}}$ concentration in the afternoon and $\mathrm{NO}_{2}$ during the morning.

Based on this prior knowledge 24 ensemble members were constructed. In this experiment the 11 meteorological ensemble members calculated by MM5, and driven by the PEARP system. Thirteen other ensemble members are derived by emissions, chemical or chemical related considerations. These perturbations were based on the meteorological PEARP-MM5 control run. Two different years for the EMEP emission inventory - 2002 and 2003 were chosen and the remainder perturbations were performed based on the 2003 emissions inventory. Vertical emissions distributions were taken into account considering different disaggregating factors between 2 and 3 levels. Since the actual validated operational runs with 2 vertical levels for annual emissions all the remainder disturbances were performed attending this consideration. Namely, a lag of one hour $( \pm)$ on the hourly profiles for all the activity sectors; VOC emissions from solvent use perturbed $( \pm 40 \%$, based on uncertainties emissions estimation taken from Theloke and Friderich, 2000 and the IPCC, 2006), traffic $\mathrm{NO}_{\mathrm{x}}$ emissions were considered to vary between $\pm 20 \%$ (Kühlwein and Friedrich, 2000). Random hourly perturbations are applied to the gas chemical species at the boundaries and to the attenuation coefficient that is calculated into the CHIMERE meteorological diagnostic pre-processor. The traffic behaviour at Mondays and Fridays during the morning was also included in one chemical ensemble member, in this case multiplying factors without considering emitted mass conservation from the inventory were applied between $5 \mathrm{H} 00$ and $8 \mathrm{H} 00$ UTC. Figure 1 summarises all the perturbations considered into the ensemble air quality system.

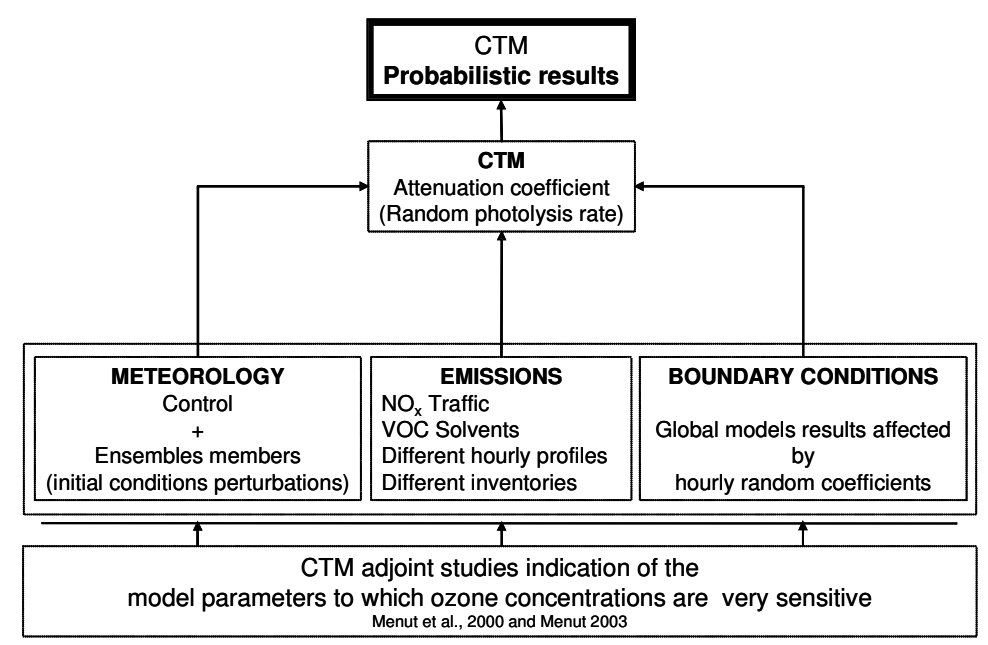

Figure 1: Disturbances introduced into the ensemble design. 


\section{Weather conditions and observed ozone concentrations during the simulation period}

Between the 23 of July and the 3 of August Europe as experienced several days of high concentrations of maximum ozone values daily values. These high values started to appear over Italy, and eastern part of Italy; then the high maximum ozone plume is produced over the central and western part of Europe, and finally it disappears from southern European countries around the 3 of August (see the evolution of the analysed CHIMERE results produced during the summer season of 2006 at URL 3). It coincides with the end of the heat wave of 2006 that has affected several countries. In order to capture these air pollution events over the domain of simulation, the air quality systems was "speened-up" for a period of 5 days, the period of simulations started with the meteorological forecast $19^{\text {th }}$ of July, at $18 \mathrm{H} 00$ UTC ending the forecast that starts at the $3^{\text {rd }}$ of august.

\section{RESULTS}

To be consistent with the PREVAIR system scores, the same coefficients for measuring the model skill were applied, namely, the BIAS, the root mean square error (RMS) and the Pearson correlation coefficient (COR). The BIAS is the sum of the model forecast minus the observations divided by the number of observations, at each location; the RMS, is the root mean error and gives an indication of the model skill for ozone concentration magnitude; finally, the COR, is the Pearson linear coefficient between the model results and the observations, permitting to obtain an overview of the maximum and minimum values forecast model skill

In order to have a robust measure of the central value of the simulated concentration distribution at each locations, model results were evaluated comparing the median of the ensemble results at each station.

The ozone stations database comprises several European countries: France, United Kingdom, Belgium, Suisse, The Netherlands, Germany the Check Republic and Spain. Unfortunately, during the period under evaluation the information of most of the countries is not present and only France and Germany are represented in this study.

Tables 1 to 3 summarise the distribution of the RMS, COR and BIAS calculated. The number of stations may vary according to the existence or not of measured data. The skill of the model was evaluated considering the type of the station, namely, rural, peri-urban and urban.

The air quality model systems tend to present an error magnitude between (Table 1) 30 and $40 \mu \mathrm{g} . \mathrm{m}^{-3}$ for all type of stations. The second more frequent class of error is between 40 and $50 \mu \mathrm{g} \cdot \mathrm{m}^{-3}$ at D1 and D2 for urban and peri-urban site locations. Globally, it is on D2 at rural sites that the system presents small errors on the ozone forecast magnitude.

The BIAS score is helpful in order to understand of the model over or under predicts the ozone concentrations. Regarding Table 3, results on the deviation between model results and observations indicates that the model under-predicts the measured ozone concentrations. Model errors spans $-60 \mu \mathrm{g} \cdot \mathrm{m}^{-3}$ and $+40 \mu \mathrm{g} \cdot \mathrm{m}^{-3}$. Due to the model system horizontal grid resolution, rural stations present errors of $\pm 20 \%$ for $84 \%$ for forecast day D1. Over most of the peri-urban and also over urban sites the model under predicts 
the measured value between -30 and -20 concentration units. But, it is in the urban sites that the air quality system tends to over predict ozone concentrations. Differences between D1 and D2 do not seem very significant for this parameter.

The model system is able to better reproduce maximum and minimum values of the measured ozone tome series for peri-urban stations sites (Table 2). More then $86 \%$ of the station have correlation coefficients between 0.7 and 0.8 . Results for rural and urban present correlation coefficients results are preferable encountered between correlation coefficient values between 0.6 and 0.8 . The degradation of the forecast for D2 is more visible for peri-urban sites were the percentage of locations with correlation coefficients between 0.7-0.8 increases.

Table 1: RMS distributions of skill score for D1 and D2 forecast days $\left(\mu \mathrm{g} . \mathrm{m}^{-3}\right)$ calculated for Rural, peri-urban (PURB) and urban (URB) stations, where: \% - percentages and \# number of stations.

\begin{tabular}{|c|c|c|c|c|c|c|c|c|c|c|c|c|}
\hline \multirow{3}{*}{ Classe } & \multicolumn{4}{|c|}{ RURAL } & \multicolumn{4}{|c|}{ PURB } & \multicolumn{4}{|c|}{ URB } \\
\hline & \multicolumn{2}{|c|}{$\%$} & \multicolumn{2}{|c|}{ \# } & \multicolumn{2}{|c|}{$\%$} & \multicolumn{2}{|c|}{ \# } & \multicolumn{2}{|c|}{$\%$} & \multicolumn{2}{|c|}{ \# } \\
\hline & D1 & D2 & D1 & D2 & D1 & D2 & D1 & D2 & D1 & D2 & D1 & D2 \\
\hline $10 \quad \mathrm{RMS}<20$ & 4.9 & 4.9 & 4 & 4 & 4.4 & 5.1 & 3 & 3 & - & & - & \\
\hline $20 \quad \mathrm{RMS}<30$ & $\begin{array}{r}2 \\
0.7\end{array}$ & 25.6 & 17 & 21 & $\begin{array}{r}2 \\
2.1\end{array}$ & $\begin{array}{r}2 \\
2.0\end{array}$ & 15 & 13 & $\begin{array}{r}1 \\
5.3\end{array}$ & $\begin{array}{r}1 \\
5.3\end{array}$ & 9 & 9 \\
\hline $30 \quad \mathrm{RMS}<40$ & 48.8 & 43.9 & 40 & 36 & 33.8 & 37.3 & 23 & 22 & 47.5 & 44.1 & 28 & 26 \\
\hline $40 \quad \mathrm{RMS}<50$ & 22.0 & $\begin{array}{r}2 \\
2.0\end{array}$ & 18 & 18 & 27.9 & 27.1 & 19 & 16 & 25.4 & 30.5 & 15 & 18 \\
\hline $50 \quad \mathrm{RMS}<60$ & 3.7 & 2.4 & 3 & 2 & $\begin{array}{r}1 \\
1.8\end{array}$ & 8.5 & 8 & 5 & 8.5 & $\begin{array}{r}1 \\
0.2\end{array}$ & 5 & 6 \\
\hline $60 \quad \mathrm{RMS}<70$ & & 1.2 & & 1 & & & & & 3.4 & & 2 & \\
\hline
\end{tabular}

Table 2: COR distributions of skill score for D1 and D2 forecast days $\left(\mu \mathrm{g} . \mathrm{m}^{-3}\right)$ calculated for Rural, peri-urban (PURB) and urban (URB) stations, where: \% - percentages and \# number of stations.

\begin{tabular}{|c|c|c|c|c|c|c|c|c|c|c|c|c|}
\hline \multirow{3}{*}{ Classe } & \multicolumn{4}{|c|}{ RURAL } & \multicolumn{4}{|c|}{ PURB } & \multicolumn{4}{|c|}{ URB } \\
\hline & \multicolumn{2}{|c|}{$\%$} & \multicolumn{2}{|c|}{ \# } & \multicolumn{2}{|c|}{$\%$} & \multicolumn{2}{|c|}{ \# } & \multicolumn{2}{|c|}{$\%$} & \multicolumn{2}{|c|}{ \# } \\
\hline & D1 & D2 & D1 & D2 & D1 & D2 & D1 & D2 & D1 & D2 & D1 & D2 \\
\hline $0.1 \quad \mathrm{COR}<0.2$ & & 1.2 & & 1 & & & & & & & & \\
\hline $0.2 \quad \mathrm{COR}<0.3$ & 1.2 & & 1 & & - & & & & & 1.7 & & 1 \\
\hline $0.3 \quad \mathrm{COR}<0.4$ & 1.2 & 1.2 & 1 & 1 & - & 4.4 & & 3 & 1.7 & 1.7 & 1 & 1 \\
\hline $0.4 \quad \mathrm{COR}<0.5$ & 1.2 & 3.7 & 1 & 3 & 2.9 & 2.9 & 2 & 2 & 8.5 & 1.7 & 5 & 1 \\
\hline $0.5 \quad \mathrm{COR}<0.6$ & $\begin{array}{r}1 \\
2.2\end{array}$ & $\begin{array}{r}1 \\
1.0\end{array}$ & 10 & 9 & 4.4 & 2.9 & 3 & 2 & 5.1 & $\begin{array}{r}1 \\
6.9\end{array}$ & 3 & 10 \\
\hline $0.6 \quad \mathrm{COR}<0.7$ & 22.0 & 23.2 & 18 & 19 & 5.9 & 8.8 & 4 & 6 & 30.5 & 35.6 & 18 & 21 \\
\hline $0.7 \quad \mathrm{COR}<0.8$ & 42.7 & 45.1 & 35 & 37 & 48.5 & 61.8 & 33 & 42 & 45.8 & 33.9 & 27 & 20 \\
\hline $0.8 \quad$ COR $<0.9$ & 1 & 1 & 16 & 12 & 38.2 & 19.1 & 26 & 13 & 8.5 & 8.5 & 5 & 5 \\
\hline
\end{tabular}




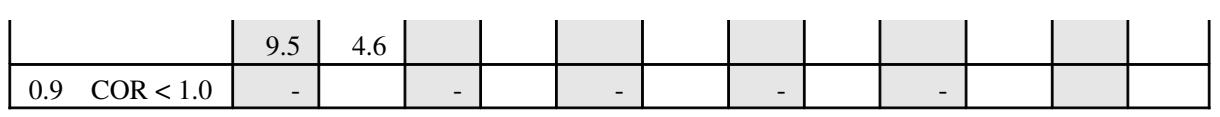

Table 3: BIAS distributions of skill score for D1 and D2 forecast days $\left(\mu \mathrm{g} \cdot \mathrm{m}^{-3}\right)$ calculated for Rural,

peri-urban (PURB) and urban (URB) stations, where: \% - percentages and \# number of stations.

\begin{tabular}{|c|c|c|c|c|c|c|c|c|c|c|c|c|}
\hline \multirow{3}{*}{ Classe } & \multicolumn{4}{|c|}{ RURAL } & \multicolumn{4}{|c|}{ PURB } & \multicolumn{4}{|c|}{ URB } \\
\hline & \multicolumn{2}{|c|}{$\%$} & \multicolumn{2}{|c|}{ \# } & \multicolumn{2}{|c|}{$\%$} & \multicolumn{2}{|c|}{$\#$} & \multicolumn{2}{|c|}{$\%$} & \multicolumn{2}{|c|}{ \# } \\
\hline & D1 & D2 & D1 & D2 & D1 & D2 & D1 & D2 & D1 & $\mathrm{D} 2$ & $\mathrm{D} 1$ & $\mathrm{D} 2$ \\
\hline$-60 \quad$ BIAS $<-50$ & & 1.2 & & 1 & & & & & 1.7 & & 1 & \\
\hline$-50 \quad$ BIAS $<-40$ & 1.2 & & 1 & & 2.9 & 1.5 & 2 & 1 & 5.1 & 3.4 & 3 & 2 \\
\hline$-40 \quad$ BIAS $<-30$ & 3.7 & 3.7 & 3 & 3 & $\begin{array}{r}2 \\
0.6\end{array}$ & $\begin{array}{r}1 \\
8.2\end{array}$ & 14 & 12 & $\begin{array}{r}1 \\
3.6\end{array}$ & $\begin{array}{r}1 \\
6.9\end{array}$ & 8 & 10 \\
\hline$-30 \quad$ BIAS $<-20$ & 11 & 9.8 & 9 & 8 & 27.9 & 33.3 & 19 & 22 & 20.3 & 20.3 & 12 & 12 \\
\hline$-20 \quad$ BIAS $<-10$ & 32.9 & 37.8 & 27 & 31 & 27.9 & 27.3 & 19 & 18 & $\begin{array}{r}1 \\
8.6 \\
\end{array}$ & $\begin{array}{r}1 \\
6.9 \\
\end{array}$ & 11 & 10 \\
\hline$-10 \quad$ BIAS $<0$ & 35.4 & 31.7 & 29 & 26 & $\begin{array}{r}1 \\
3.2 \\
\end{array}$ & $\begin{array}{r}1 \\
6.7 \\
\end{array}$ & 9 & 11 & $\begin{array}{r}1 \\
6.9 \\
\end{array}$ & 22.0 & 10 & 13 \\
\hline $0 \quad$ BIAS $<20$ & $\begin{array}{r}1 \\
5.8 \\
\end{array}$ & 15.9 & 13 & 13 & 4.4 & 3.0 & 3 & 2 & 23.7 & & 14 & 12 \\
\hline $20 \quad$ BIAS $<40$ & & & & & 2.9 & & 2 & & & & & \\
\hline
\end{tabular}

The score calculated by Honoré et al. (JGR, submitted) for the PREV'AIR system, as a mean of all stations between 2003 and 2006 summer seasons for forecast D0 are: BIAS 12.3, RMS 28.2 and COR 0.67. In the present study the system was evaluated under a situation were high ozone concentration were measured during 2006. This explains the higher values for the RMS and the under prediction of model results indicated by the BIAS. In general, correlation coefficients are of the same order for all type of stations. Regarding the spatial distribution of the coefficient correlations for forecast day D1, it can be observed that the model is unable to reproduce maximum and minimum values of the time series mostly over the North and Central-eastern part of Germany (see Figure 2). The Auvergne region and the Mediterranean Pyrenees are the locations over France were the correlation coefficients show also results with values lesser than 0.5 .

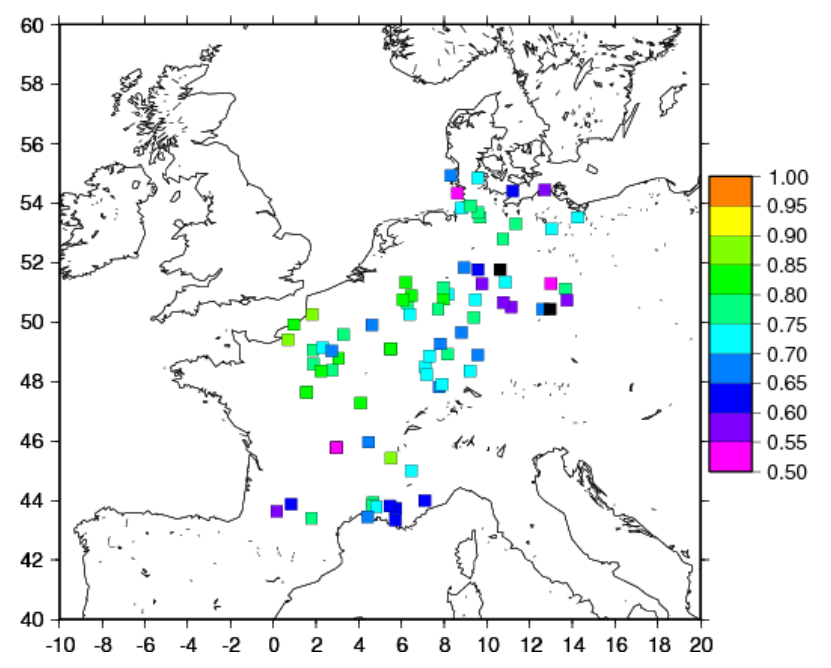


Figure 2: Pearson's correlation coefficient for rural stations for forecast DI.

\section{CONCLUSIONS}

A meteorological chemical air quality model ensemble system was planned and evaluated during the heat wave of 2006 over Western Europe. This system was designed based on ensemble meteorological runs and also on the previous knowledge form chemical adjoint results on most sensitivity parameters to the model.

The median of the air quality system ensemble results were compared to the observations. For all the calculated skill scores classes, the degradation of the forecast skill between D1 and D2 is not very significant. In general, air quality model results are under predicted, more frequent RMS error values are between 30 and $40 \mu \mathrm{g} . \mathrm{m}^{-3}$. Pearson correlation coefficients have best fits over peri-urban sites, indicating that the model is able reproduce better the maximum and minimum of the results distributions at these sites. Concerning spatial distribution of the COR at forecast D1, the variability introduced by the ensemble members is not sufficient to reproduce time series in the northern, near the coast, and central-eastern part of Germany as well as over the French mountain regions of Auvergne and Mediterranean Alpes. These results may be justified by the coarse model resolution.

\section{REFERENCES}

Bessagnet B., Hodzic A., Vautard R., Beekmann M., Cheinet S., Honoré C., Liousse C., Rouil L., 2004, Aerosol modeling with CHIMERE - Preliminary evaluation at the continental scale. Atmos. Environ., 38, 2803-2817.

Chiriaco, M., Vautard, R., Chepfer, H., Haeffelin, M., Wanherdrick, Y., Morille, Y., Protat, A., and J. Dudhia 2005, The Ability of MM5 to simulate Ice clouds: Systematic Comparison between Simulated and Measured Fluxes and Lidar/Radar profiles at SIRTA atmospheric observatory. Monthly Weather Review, 134, 897-918.

Dabberdt, W. F and E. Miller, 2000, Uncertainty, ensembles and air quality dispersion modeling: applications and challenges, Atmos. Environ., 34, pp. 4667-4673.

Delle Monache, L., X. Deng, Y. Zhou, and R. Stull, 2006a, Ozone ensemble forecasts: 1. A new ensemble design, J. Geophys. Res., 111, D05307, doi:10.1029/2005JD006310.

Dudhia, J., 1993, A nonhydrostatic version of the Penn State-NCAR mesoscale model: Validation tests and simulation of an Atlantic cyclone and cold front. Monthly Weather Review, 121, 1493-1513.

Galmarini, S., R. Bianconi, W. Klug, T. Mikkelsen, R. Addis, S. Andronopoulos, P. Astrup, A. Baklanov, J. Bartniki, J.C. Bartzis, R. Bellasio, F. Bompay, R. Buckley, M. Bouzom, H. Champion, R. D’Amours, E. Davakis, H. Eleveld, G.T. Geertsema, H. Glaab, M. Kollax, M. Ilvonen, A. Manning, U. Pechinger, C. Persson, E. Polreich, S. Potemski, M. Prodanova, J. Saltbones, H. Slaper, M.A. Sofiev, D. Syrakov, J.H. 
Sørensen, L. Van der Auwera, I. Valkama, R. Zelazny, 2004, Ensemble dispersion forecasting-Part I: concept, approach and indicators, Atmos. Environ., 38, 4607-4617.

Hamill, T. M., S. L. Mullen, C. Snyder, Z. Toth and D. P. Baumhefner (2000). Ensemble Forecasting in the Short to Medium Range: Report from a Workshop, Bull. Am. Meteorol. Soc., 81, 2653-2664.

Honoré, C.; Rouil, L.; t Vautard, R.; Beekmann, M.; Bessagnet, B.; Malherbe, L.; Meleux, F.; Dufour, A.; Elichegaray, C.; Flaud, J-M.; Menut, L.; Martin, D.; Peuch, V-H.; Poisson, N., Predictability of regional air quality in Europe: the assessment of three years of operational forecasts and analyses over France, Journal of Geophysical Reseach, under revision.

IPCC (2006). IPCC Guidelines for National Greenhouse Gas Inventories (http://www.ipcc-nggip.iges.or.jp/public/2006gl/pdf/3_Volume3/V3_5_Ch5_Non_Ener gy_Products.pdf).

Kühlwein, J., and R. Friedrich (2000). Uncertainties of Modelling Emissions from Road Transport. Atmos. Environ. 34, pp. 4603-4610.

Lorenz, E. N., 1963, Deterministic non-periodic flow. J. Atmos. Sci., 20, pp. 130-141.

Menut, L., 2003, Adjoint modeling for atmospheric pollution process sensitivity at regional scale, J. Geophys. Res., 108(D17), 8562, doi:10.1029/2002JD002549, 2003.

Menut, L., R. Vautard, M. Beekmann, C. Honoré, 2000, Sensitivity of photochemical pollution using the adjoint of a simplified chemistry-transport model, J. Geophys. Res., 105(D12), 15379-15402, 10.1029/1999JD900953, 2000.

Theloke, J. and Friedrich, R., 2002, NMVOC Emissions from Solvent Use in Germany 2000. Annual Report 2001 of the EUROTRAC subproject Generation and evaluation of emission data - GENEMIS. Munich 2002.

Vautard R., M. Beekmann, J. Roux, D. Gombert, 2001, Validation of a deterministic forecasting system for the ozone concentrations over the Paris area. Atmos. Environ., 35 , pp. 2449-2461.

Vautard, R et al (2006). Is regional air quality model diversity representative of uncertainty for ozone simulation? Geophys. Res. Lett., 33, L24818, doi: 10.1029/2006GL027610.

URL 1: http://prevair.ineris.fr/en/introduction.php

URL 2: http://www.emep.int

URL 3: http://prevair.ineris.fr/fr/prevision_o3.php 